\title{
PROPOSICIONES CON TÉRMINOS NEGATIVOS
}

\author{
Angel Muñoz García \\ Universidad de Zulia (Venezuela)
}

El término, como signo lingǘstico, tiene habitud a compararse con otro; ${ }^{1}$ comparatio sive habitudo, dice Algazel. ${ }^{2} \mathrm{Y}$ al actualizarse esa habitud, lo hace -entre otros aspectos- como composición y división. ${ }^{3}$ El término racional tiene aptitud o habitud a compararse con el término hombre, por medio de lo que Aristóteles llamaría composición proposicional; pero ya este concepto trae consigo (los opuestos se aclaran más al compararlos ${ }^{4}$ ) el de división; por lo que hubo de completar su esquema con la proposición negativa.

Acerca del aristotélico de cualquiera se predica uno de los dos contradictorios, ${ }^{5}$ es significativa la insistencia de los medivales en que su sentido no es que de cualquier sujeto puede predicarse uno de los dos contradictorios; sino que el quolibet ha de entenderse no de quolibet significative sumpto, sino de quolibet supponente significative: ${ }^{6}$ chymaera est homo y chymaera est non-homo son ambas falsas, ya que su sujeto significa un inexistente; mientras que de chymaera est homo y chymaera non est homo la primera es falsa y la segunda verdadera.

1 Quieren ser estas páginas un pequeño homenaje a Alberto de Sajonia, Rector de París y fundador de la Universidad de Viena, en su Año Centenario.

Aptum natum est supponere in propositione: Alberto de Sajonia Perutilis Logica, Ed. A. Muñoz, Maracaibo, 1988, n. 16 (en adelante cit. P.L.); Ockham, Summa Logicae I, c. 1, ed. Boehner-Gal-Brown, New York, 1974, p. 9 (en adelante S.L.)

2 Tractatus de Logica, Maneria tertia, 2, ed. Ch. Lỏhr. Logica Algazelis. Introduction and critial text, en «Traditio», XXI, 1965, p. 255 (en adelante cit. Algazel).

3. In re, et affirmatio et negatio aequales sunt. Aequaliter affirmatio et negatio de veritate et falsitate participant: Boecio, In Librum «De Interpretatione» Editio Secunda, ed. Migne, Patrologia Latina, 64, 401 B (en adelante cit. Secunda).

4 Opposita iuxta se posita magis elucescunt: P.L. n. 133.

5 Alterum contradictoriorum dicitur de quolibet: Metaph. IV, c. 7, 1011b 14; Top. VI, c. 6, 143b 15s.

6 No «de cualquiera tomado significativamente», sino «de cualquiera que supone significativamente»: S.L. II, c. 12, p. 184. 
Decir la verdad no es sino negar lo falso; ${ }^{7}$ esto es, es imposible que todo sea falso: porque necesariamente una de las dos (afirmación/negación) ha de ser verdadera. ${ }^{8}$

Así, para Aristóteles todas las proposiciones son asertos apofánticos, verdaderos o falsos, ya estén afirmados o negados; pero se necesita de la existencia de ambos y de ambos valores de verdad, para que pueda haber apofanticidad en el lenguaje. ${ }^{9}$

Por ello Boecio sentencia: Toda enunciación es afirmación o negación..$^{10} \mathrm{Y}$ Aristóteles establece $^{11}$ que dado el es en tercer adyacente, puede haber dos modos de formular la contradicción:
1) $S$ es $P$
2) $S$ es $P$
3) $S$ es no-P
4) $S$ no es no-P

las proposiciones de cada línea son contradictorias, -la negación de 1) es 2) y no 3) $)^{12}-$ y cada negativa se origina en su correspondiente afirmativa, la 2) de la 1), la 4) de la 3).

Este doble modo de contradicción admite la posibilidad de que cualquier término pueda negarse. Y el que esté tomando a 1) y 3) como afirmativas ambas y a 2) y 4) cono negativas confirma la diferenciación entre la negación de términos y la de proposiciones. Más aún: en el mismo capítulo insiste en la distinción entre proposiciones con forma negativa -2) y.4) del esquema-y las que son afirmaciones originadas de negaciones (la 3) se origina de 2); pero ello no qyiere decir que sea negativa).

Teofrasto hubiera diseñado este esquema como
1) $S$ es $P$
2) $S$ es no es $P$
3) $S$ no es no-P
4) $S$ es no- $P$

en donde, además de las relaciones de contradicción del esquema aristotélico -entre 1) y 2), y entre 3) y 4)-queda más visualizable que 3) se origina de 1) (de la afirmación finita se deriva la negación infinita, y la afirmativa 4) de la negación 2). Quizá por eso llamó Teofrato a 3) y 4) ek metathéseos, esto es por transposición: bien sea por transposición del no, que de afectar a es pasa a hacerlo a $\mathrm{P}$-en 2) y 4)-, ya como trasnsposición local de las proposiciones 3) y 4) en el esquema, como quieren otros autores. ${ }^{13}$

Tales son las proposiciones privativas. La nomenclatura pudo deberse a la figuración en ellas de términos a los que Aristóteles llamó alfa privativos. ${ }^{14} \mathrm{O}$ quizá a la tradición árabe,

\footnotetext{
7 Metaph. IV, c. 8, 1012b 10-13.

8 De Interpr., c. 7, 17b 26ss.

9 Est autem simplex enuntiatio vox significativa de eo quod est aliquid, vel non est... Affirmatio est enuntiatio alicuius de aliquo. Negatio vero est enuntiatio alicuius ab aliquo: De Interpr., cc. 5-6, 17a 22-26.

10 Omnis enuntiatio, aut affirmatio aut negatio est: Secunda 454 A.

11 De Interpr., c. 10, 19 b 19-31; Anal. Pro. I, c. 46, principalmente 51 b 36 - 52a 17.

12 Anal. Pro. I, c. 46, 52a 22ss.

13 Repici, L., La Logica di Teofrasto, Bolonia, 1977, pp. 64-67.

14 Metaph. V, c. 22, 1022 b 32.
} 
transmisora de Aristóteles a Occidente, que empleó el término $m a^{\prime} d \bar{u} l a h$, vertido al latín en privativa, infinita, remotiva. ${ }^{15}$ De una lectura de $A$ lgaze ${ }^{16}$ se desprende que:

- El término privativo significa lo contrario del finito.

- La proposición con predicado privativo es afirmativa.

- Y se llama privativa.

- Aunque es translata a cierta apariencia de negativa.

Averroes ${ }^{17}$ habla de proposiciones infinitas (remotivae) en las que el predicado es un término infinito (imperfectum), como Socrates est non sanus. De ellas unas son privativas, (si su predicado es privativo, Socrates est caecus, Plato aegrotat). Y aclara que tales términos imperfectos no se utilizan en árabe, pero tienen el mismo valor que los privativos. Como contraparte, otros idiomas que utilizan términos infinitos tienen el peligro de caer en ambigüedad, ya que el sentido puede ser el del privativo árabe, o de negación absoluta. La observación del Comentador puede hacer más claro a Algazel: «No es, dice, que 'Petrus est non sapiens' es negativa. Su sentido es 'Petrus est insipiens': una afirmativa privativa, translata, una de las 'ek metathéseos' de Teofrasto»' ${ }^{18}$. Boecio no deja lugar a dudas. ${ }^{19}$

Estando el término privativo en la proposición en relación ya directa con un determinado sujeto, pordríamos considerar que el que sea privativa o infinita no depende solamente de la forma del predicado (ciego o no-vidente), sino de tal relación específica. Podemos tomar a $P$ Pdro es injusto y Pedro es no justo, como privativas ambas, pues aunque la segunda tenga un predicado infinito, es claro, si la proposición es verdadera, que se entiende en sentido privativo. Los mismos medievales, sentando la proposición como propia y estrictamente falsa, condescienden con el lenguaje usual y la aceptan como verdadera. ${ }^{20}$ Pero las diferenciaron cuando fue necesario. Además del citado texto de Alberto, Ockham p.ej. precisa que, mientras la infinita se expone por otras dos, sustituyéndose en una de ellas el término infinito por aliquid (asinus est non-homo = asinus est aliquid, et asinus non est homo), las privativas tienen más de dos exponentes: $:^{21}$ iste est caecus $=$ iste est aliquid, et iste est natus videre, et iste per naturam nunquam poterit videre.

15 Wolfson, M., Infinite and privative judgments in Aristotle, Averroes and Kant, en «Philosophy and phenomenological research», 8 1947/48, p. 176.

16 Similiter errant in categorica, et putant quod haec "Petrus est insipiens» sit negativa. Est autem affirmativa; eius enim intentio est significare eum esse stultum. Et haec dicitur propositio privativa, cum revera sit affirmativa, sed est translata ad formam negationis: Algazel, Maneria tertia, 2, p. 254.- Uno de los sentidos actuales de ma'dūlah es desviada, totalmente adecuable con el translata de Algazel, que sugiere el origen teofrástico.

17 De Interpretatione IV, Venecia, 1574, vol. I, 2, f. 41.

18 Wolfson, op. cit., pp. 197-201.

19 Formam quidem affirmationis tenet, sed privationem praedicat: In Librum «De Interpretatione» Editio Prima, ed. Migne, Patrologia Latina, 64, 344 C (en adelante cit. Prima).

20 P.L. nn. 72-79.

21 S.L.II, c. 12, p. 12, p. 183, y c. 13, p. 285 respectivamente.- Similarmente Alberto de Sajonia: «Brunellus est non homo» valet istam: «Brunellus est, et non est homo». 
Como sea, hay algo incuestionable para todos: privativas e infinitas son afirmativas. Aristóteles es tajante: privación y posesión se dicen acerca de lo mismo: ${ }^{22}$ esto es, ambas se dicen afirmativamente de lo mismo. Y explícitamente en los Analíticos sostiene que «es no blanco» y «no es blanco» tienen significación diferente, siendo una afirmación y la otra negación. ${ }^{23}$

Cuanto a las infinitas, cabría preguntar qué significan exactamente. Incluso, previamente, si en verdad significan algo, reflejan o no alguna realidad, dicen o no algo de ésta. ¿Qué dice de $S$ exactamente $S$ es no-P? Ante todo, afirma la existencia de $S$. Quizá no sepamos qué es $S$, pero es. Bastará para probar esto tres razones:

1) es afirmativa; luego es falsa si no existe el sujeto.

2) es de tercer adyacente; luego presupone la de segundo adyacente, $S e s^{24}$ (afirmación de la existencia del sujeto, 0 abreviatura de $S$ est ens vel entia). ${ }^{25}$

3) su exponente afirma que $S$ est aliquid. ${ }^{26}$

Segundo: ¿Qué dice de cómo es $S$ ? Estrictamente hablando, el infinito no es término y no significa; así que una proposición con tal predicado resulta en realidad sin predicado, de segundo adyacente; y nada dice de qué o cómo es S. Boecio es claro. ${ }^{27}$ La negación parece «dejarnos sin predicación y predicado»; el no significar una cosa, es no significar nunguna. ${ }^{28}$

Sin embargo, si aceptamos que aunque «amplia» e indeterminadamente algo significa, concluiremos que es una proposición de tercer adyacente, verdadera predicación de una (peculiar) propiedad equívoca, de gran extensión, que por decir de $S$ casi todo, dice casi nada del mismo. Pedro es no-ave niega ave de Pedro, -0 mejor predica de Pedro la ausencia de la propiedad ave-y deja todas las demás. Lo que replantea la cuestión de si hay o no propiedades negativas. Si para Russell (y su el actual Rey de Francia ...) lo no existente no tiene propiedades, podríamos preguntar si lo existente puede tener no-propiedades. ¿Está en mí la no-cuadrupedez? ¿Simplemente no está o es una carencia?

Se podría responder que -P no es precisamente una propiedad negativa, (la propiedad no ser ave), sino cualquier propiedad «positiva» distinta de P. Aunque sin saber cuál concreta sea.

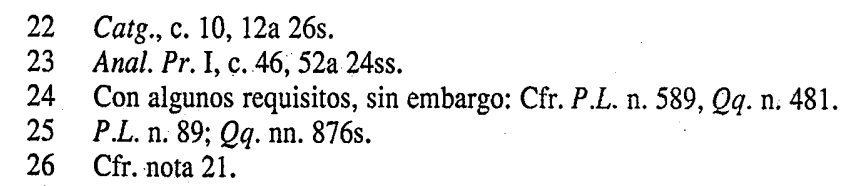

27 Qui enim dicit «homo non ambulat» ambulationem ab homine tollit, non de homine praedicat. Quare negatio plus quam affirmatio est. Si enim affirmatio esset, id est si verbum esset infinitum, aliquid de aliquo praedicaret. Nunc autem aliquid ab aliquo tollit: Secunda 524 C.

28 Oportet ... id quod affirmatio praedicavit et iunxit, idem negatio dividat et abiungat; et id quod de subiecto affirmatio praedicavit, de eodem negatio neget.- Affirmatio de alia re aliam rem praedicat eique coniungit. Negatio vero a qualibet re quamlibet rem praedicando tollit: De Divisione, ed. Migne, Patrologia Latina, 64, 882 A.-Cfr. Secunda 460 B, 453 C; Prima 314 A.-Commentarium in Tractatum «De Consequentiis»; (atribuído a Alberto de Sajonia), nn.2.1.13.4/7; 2.5.8.5; 3.2.41s. de la ed. crítica que actualmente preparo (en adelante cit. Comm): quidquid affirmatio affirmat, negatio negat; negatio non plus negat quam affirmatio affirmat. 
Con lo que $-\mathrm{P}$ representaría la disyunción cuasi-infinta de todas las propiedades menos $\mathrm{P}$ : Pedro es anfibio, o mamífero, o cuadrado, o feldespático, o ... Si alguien, apurando más, dijera que si la proposición es verdadera, la disyunción ha de estar formada solamente por disyuntas que hagan verdadera a la proposición inicial, la respuesta es obvia: ninguna razón lógica obliga a una disyunción así, $O$ que se prtendiera que los predicados de las disyuntas hubieran de ser exclusivamente inferiores lógicos del término no-ave. ${ }^{29}$

Siendo esto así, puede suceder que:

- Pedro es no-vidente: estrictamente habría que decir que es falsa, pues afirmando la existencia de Pedro, y la ausencia de visión en él, denota que Pedro no es naturalmente apto para ver; habla de ausencia de visión cuando tendría que hablar de carencia de ella (Pedro es invidente). Así como el punto es indivisible es falsa, por cuanto del punto (que no acepta división) se dice que no está dividido, pero que por naturaleza tiene capacidad de ello. ${ }^{30}$ Implicat!.

- Pedro es no-ave: estrictamente dice que Pedro existe, que no es ave, y que no es apto naturalmente para serlo. Así, sería verdadera. Pero, puesto que Pedro es, algo es; no es ave; debemos atribuirle pues, cualquier otra propiedad. Pero, ¿cómo interpretar entonces la proposición? Como verdadera (Pedro es mamífero) o como falsa (Pedro es anfibio)?

Una respuesta es: al no saber qué significa exactamente no-ave, no podemos decir si es verdadera o falsa; como en el caso de Pedro es estreglotípico, de cuyo predicado ignoramos el significado. Otra es tomarla como verdadera, ya que dice que la propiedad ave no está en Pedro ni le corresponde por naturaleza. Respuesta, parece, del hablante común; de los medievales, analistas del lenguaje común; de Kant. ${ }^{31}$ Tercera respuesta: no sabemos si es verdadera o falsa, (abriéndonos al campo de la trivalencia, que no podemos tocar aquí). Cabría una cuarta: considerarla auténtica predicación, de una propiedad peculiar que, debido a su gran extensión, resulta de hecho equívoca. Si observé la osa es ambigua debido a la equivocidad de su predicado, también lo será Pedro es no-ave cuyo predicado puede referirse al anfibio, al verde, al cuadrado...2

Si el tablero de ajedrez tiene cuadros blancos, permite decir con verdad el ajedrez es blanco. Pero puedo seguir diciendo el ajedrez es no-blanco. Que la primera sea verdadera no obliga a decir el ajedrez no es negro; cuando más que el ajedrez es no-negro. Ambas -el

29 Esto nos llevaría a otro punto del que no se puede prescindir hablando desde una perspectiva medieval: el de la suposición del término infinito en estas proposiciones. Habría mucho que hablar sobre las relaciones entre suposición y negación. Pero nos llevaría muy lejos de los límites trazados para este trabajo. Sólo acotaré que la respuesta por este camino no alteraría cuanto vamos diciendo.

30 Cfr. P.L. nn. 77, 79.

31 Si digo del alma «ella no es mortal», me libro, mediante un juicio negativo, por lo menos de un error. Por la proposición «el alma es no mortal», he afirmado realmente, según la forma lógica, poniendo el alma en la ilimitada circunscripción de los seres no mortales: Crítica de la Razón Pura: Analítica Transcendental I, c. 1, secc. 2, ed. F. Romero, Buenos Aires, 1981, p. 218.

32 Será bueno traer aquí lo opinión de Alberto de Sajonia respecto a la extensión de estos términos: Quanto aliquis terminus finitus est minus communis, tanto ipse infinitatus erit magis communis: P.L. n. 80. 
-ajedrez es blanco y el ajedrez es no-blanco-pueden ser verdaderas a la vez; una no es la negación de la otra; aunque la negación -malignantis naturae- puede llevarnos a pensar que si A es no-negro, no es negro. No son, pues, contrarias. ${ }^{33}$ Como función de verdad e inversor del valor veritativo, $\neg$ sólo puede referirse a proposiciones; pero en una (¿supuesta?) propiedad negativa no podemos hablar de valores de verdad. Estos comienzan a tener opción sólo con la predicación: $\neg P x$. Por tanto, $S$ es no $\neg P$ no es la negación de $S$ es $P$.

Esto nos lleva a otra conclusión. Si $P x$ es falsa, será verdadera $\neg P x$. Pero con tal de que no se entienda $\neg P x$ como una proposición infinita. Posiblemente los medievales hubieran preferido simbolizar es falso que $x$ es $P$ como $\neg(P x)$, para dejar más claro que se trata de una negación proposicional y no del término. Pero aún podrían exigir, más: en el caso de $\neg P x$ (o de $\neg P$ ), exigirían distinguir el operador $\neg$ para los casos de ausencia (infinitación), y los de carencia (privación).

Pasando ya a la proposición estrictamente negativa: ya vimos que $S$ no es $P$ nada dice de $S$; ni siquiera su existencia; así la proposición fuera verdadera..$^{34}$

Al negar la relación entre $S$ y $P$, la negación niega la posibilidad de juicio; destruye lo que encuentra tras de sí; ${ }^{35}$ destruye, pues, la predicación. Más aún: destruir la predicación no es una mera ausencia de ella; en homo est non albus se da tal ausencia de ella: pero en homo no est albus se niega, se excluye, se rechaza la presencia. ${ }^{36}$ Esa cierta información que proporciona la preposición negativa es una información sólo hipotética: existir $S$, deberá ser no-P o tener la cualidad $P$. En esto los medievales sí aceptarían la simbolización actual.

¿ «S NO ES $P »=« S E S N O-P » ?$

La Lógica Moderna, de carácter extensional, simboliza ambas como $(x)(S x)-P x) .{ }^{37}$ Para Hobbes y Mill es la misma proposición. Para Aristóteles y los medievales (es claro lo dicho) son distintas. Lo contrario sería admitir la convertibilidad de la afirmativa en negativa. Brunellus est non homo, con predicado estrictamente negativo (negación negante), es entender la proposición como negativa, con negación no ya al predicado, sino a la cópula es. Y su sentido es Brunellus non est homo.

Comparemos algo más la proposición negativa e infinita. Si la asistencia a la Asamblea del Club está limitada a los miembros no sancionados del mismo y digo:

I) Yo no soy miembro sancionado del club

II) No soy miembro no sancionado del club si no estoy inscrito en el Club, decir I) sería decir una proposición verdadera (aunque no puedo asistir a la Asamblea!). Pero II) es obviamente una proposición falsa. Como cuando digo

I') Yo no soy fascista o II') Yo soy no-fascista

33 Nunca lo verdadero es contrario a otro verdadero: De Interpr., c. 14, 23b $37 \mathrm{~s}$.

34 Esse enim ponit affirmatio, non esse negatio ... significatio enim de eo quod est aliquid, affirmatio est; de eo vero quod non est, negatio: Boecio, Secunda $454 \mathrm{~A}$ y D.

35. Destruit quod post se invenit: Ibidem 454 B y 455 C; Comm. $1.2 .9 .4 ; 2.1 .13 .5 ; 2.3 .2 .7 ; 2.4 .3 .3 ; 3.6 .33$.

36 Negatio aliquid alicui non inesse significat: Secunda $455 \mathrm{C}$.

37 Su «incongruencia» será el considerar negativa una fórmula cuyo signo principal no es la negación. 
esta última manifiesta un alejamiento mío del fascio, mayor que la proposición anterior. Y con proposiciones más russellianas,

A El actual Presidente de USA no es racional

B El actual Presidente de USA es no racional

aunque ambas sean falsas, el sentido de B parece ser «más falso» (si se puede hablar de «grados» en verdad y falsedad), y más ofensivo para el Presidente. Y

A'El actual Presidente de USA no es astronauta

B' El actual Presidente de USA es no astronauta

son verdaderas las dos, pero en B' el sentido es más pictórico, más atributivo, «más verdadero», (así lo ve -creo-el oyente ingenuo de tales proposiciones). Las dos (B y B') las entendemos más en alusión a la capacidad del Presidente de ser o no racional o astronauta. Así negamos la propiedad, hay una atribución o predicación (¿tácita?) de la capacidad de tenerla. Lo que no sucede con las otras dos.

El ajedrez no es azul puede ser verdadera así no exista el tablero; no así El ajedrez es noazul. De la afirmativa de predicado infinito se sigue la negativa de finito, no al contrario: luego no son equivalentes. ${ }^{38} \mathrm{La}$ negación del término predicado da una proposición afirmativa contraria; la del predicado, una negativa contradictoria.

Sin pretender considerar la proposición negativa como modal, veamos la diferencia que produce en ésta la distinta ubicación de la negación, según niegue el modum o el dictum:

$\begin{array}{ll}\text { NO es posible engordar } & \text { Es posible NO engordar } \\ \text { NO sé cómo delatarlo } & \text { Sé cómo NO delatarlo } \\ \text { NO debo subir } & \text { Debo NO subir } \\ \text { NO veo un hombre } & \text { Veo un NO hombre }\end{array}$

Nos llevaría esto a considerar la negación proposicional como una modalidad, a modo de ¿es falso que: Sx? Von Wright juzga esto detestable. ${ }^{39}$ Ciertamente tiene razón, pues no hay paralelismo con las modalidades aléticas tradicionales (necesario, posible...), como se da entre éstas y las de tipo epistémico o deóntico. Cuando, más, habría una cierta similitud en lo que se podría llamar negación de dicto (es falso que $S$ es $P$ ) y negación de re ( $S$ no es $P$ ).

Lo que procede no se pensó como respuesta a Castañeda. ${ }^{40}$ Sólo es trasvase al papel de reflexiones sobre la negación, desde la perspectiva Medieval. Pero recordaré cuatro puntos tratados que pueden ser referidos a sus planteamientos.

1.- La proposición This pencil is not blue es ciertamente ambigua, por cuanto puede entenderse también como This pencil es non-blue.$^{41}$ No estaría de más un estudio estadístico que pulsara hasta qué grado el hablante común detecta esta ambigüedad. Quizá ésta sea más

38 Cfr. Catg., c. 10, 13b 20-29.- No debe extrañar tal inferencia, ya que la negativa, al abarcar más en su pretendida pintura de la realidad, tiene más extensión.

39 Ensayo de Lógica Modal, Buenos Aires, 1970, p. 17, n. 1.

40 Castañeda, H., Negations, imperatives, colors, indexical properties, non-existence and Russell's paradox, en D. Austin (ed.) «Philosophical Analysis», 1988, pp. 169-205.

41 Id., pp. 172ss. 
frecuente en quien maneje nociones sólo de Lógica Moderna, que simboliza igual ambas proposiciones; el hablante común esté más cercano a la Medieval, analista del lenguaje natural, y para la que, en un estricto análisis de la proposición planteada, no cabe ambigüedad.

2.- Ciertamente, del hecho de que dos proposiciones sean distintas semánticamente no se puede concluir que una expresión que aparece en ambas -en nuestro caso el no- sea ambigua o tenga diferencias semánticas en sus dos figuraciones. ${ }^{42}$ Pero sí a la inversa, como en nuestro caso. Incluso, desde la perspectiva medieval, se podrían señalar diferencias sintácticas en las negaciones. Si la Moderna distingue el operador disyunción, excluyente o no, los medievales -de haber simbolizado- habrían distinguido también en la negación, como lo hicieron con otros functores (p. ej., omnes homines sunt mortales y omnes apostoli sunt duodecim). Y no sólo la negación de proposiciones de la de términos, sino incluso en ésta, la infinitante de la privante. La primera, vinculada directamente con los valores de verdad proposicionales; las otras dos no, o al menos no tan directamente. Afectando la primera también a la cualidad proposicional, no así las segundas.

3.- Se pregunta Castañeda si la diferencia entre las negaciones puede consistir en su distinta ubicación en la proposición. ${ }^{43} \mathrm{La}$ respuesta medieval es rotundamente afirmativa: evidente en las modales, según la negación afecte al modum o al dictum; radical según lo haga a la materia (término) o a la forma de la proposición (la copúla es); taxativa, pues lo que la negación niega y distribuye es lo que sigue a la negación. ${ }^{44}$

4.- Y se pregunta Castañeda en qué consista la negación genérica y cuántas especies comprende. ${ }^{45}$ Hemos visto varias clases de negación, (sin ser las únicas). Y se presentó la negación como división, o contraparte de la composición, en lo que bien puede consistir la negación genérica. Así, aunque para los medievales la negación era un concepto

42 Id., p. 175

44 Sed ad formam dicitur pertinere totum residuum; unde copula tam cathegoricae quam hypotheticae dicitur pertinere ad formam propositionis. Similiter negationes, et signa, et.ordo praedictorum ad invicem, et ....:
P.L. n. 977 .

45 Castañeda, H., cit., pp. 189 ss. 
primitivo -como señala Moody ${ }^{46}$-, podríamos proponer como su «definición»: destrucción de la composición. Y este esquema tentativo de sus clases: ${ }^{47}$

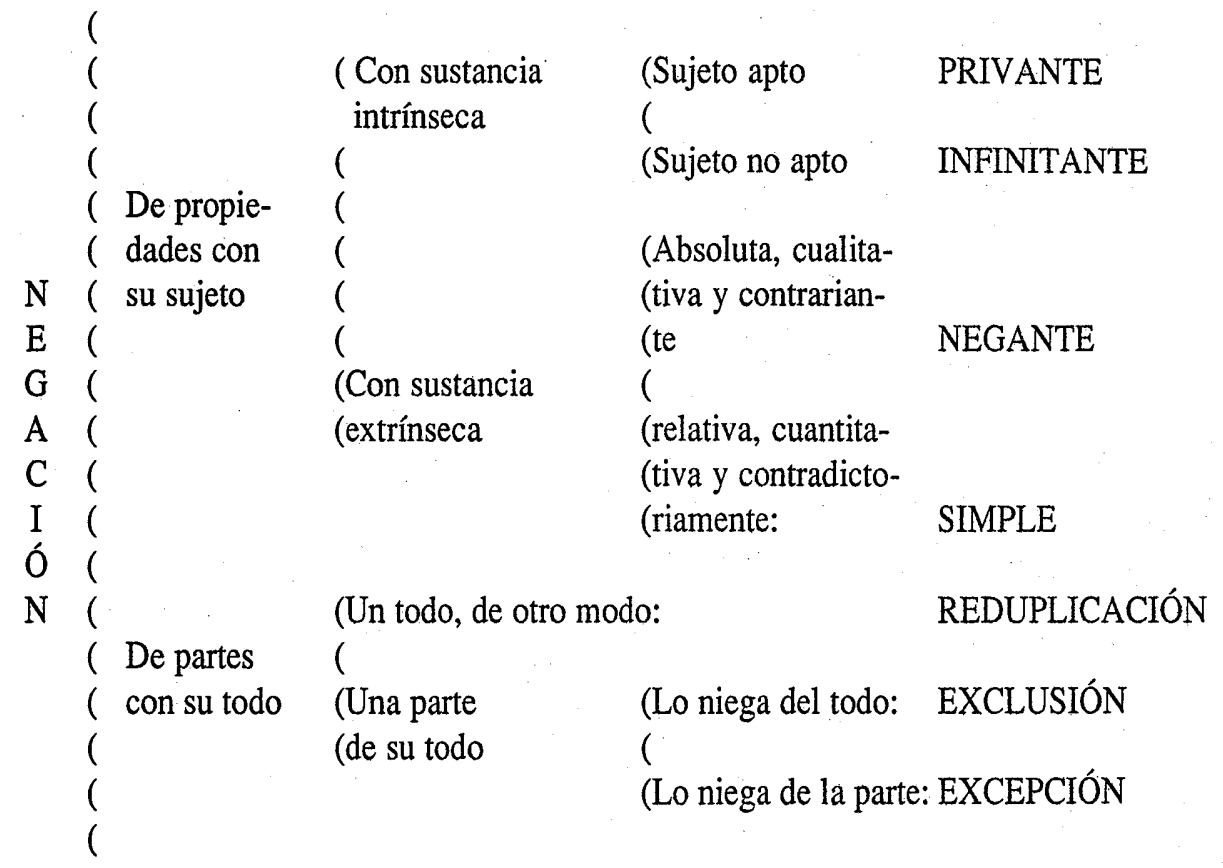

46 Moody, E., Truth and Consequence in Medieaeval Logic, Amsterdam, 1953, p. 38.

47 Podrá extrañar la inclusión aquí de los tres últimos tipos. Basta con recurrir al modo como los medievales exponían tales proposiciones, similar al utilizado en las infinitas y privativas, para topar con su contenido negativo. Si aquí no se exponen más en detalle, es porque nuestro propósito fue el estudio de la negación propiamente (o tradicionalmente llamada) tal. 